\section{Antihafteffekt durch Plasmabeschichtung}

Lersteller und Anwender von Pipetten kennen das Problem: Für viele Proben gilt es, mit höchster Präzision zu pipettieren. Dazu gehören teure Enzyme ebenso wie Proben, die nur in geringen Mengen zur Ver-

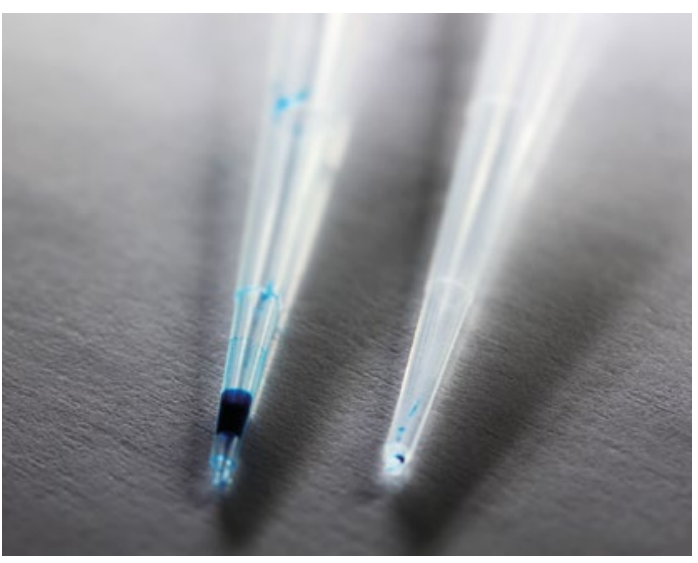

www.plasma.de fügung stehen, wie auch solche, die zur Schaumbildung neigen. Die in der Pipette verbleibende Flüssigkeitsmenge soll so weit wie möglich reduziert werden. Aus diesem Grund gehen immer mehr Hersteller dazu über, sogenannte Low Retention Pipetten- und Filterspitzen zu produzieren, indem sie eine ultrahydrophobe Oberfläche herstellen. Mit Hilfe einer Niederdruck-Plasmaanlage können Medizintechnikhersteller Pipetten aus Polypropylen (PP) im InlineProzess effizient verarbeiten. Dabei lassen sich in einem Arbeitsgang knapp 10000 Pipetten behandeln.

\section{Vernetzungsadditiv verbessert Chemikalienresistenz von UV-Lacken}

$D^{1}$ ie Firma Evonik rüstet ihre UVhärtenden Klarlacke jetzt mit dem bereits etablierten Vernetzungsverstärker Taicros aus. Dadurch werden die Chemikalienbeständigkeit und die mechanischen Eigenschaften dieser Lacke verbessert. Wie der Hersteller betont, sind UV-härtende Lacke bisher nicht resistent genug gegen chemische Einflüsse. Der Vernetzungsverstärker verbessere diese Resistenz. Die zugleich verbesserten mechanischen Eigenschaften kommen insbesondere bei der Zwischenschichthaftung in Multischichtaufbauten zum Tragen. Der Vernetzungsverstärker ist ein Reaktivverdünner, der bereits seit mehr als zehn Jahren in verschiedenen Anwendungen im gesetzt wird, so zum Beispiel in Kunststofffolien zum Schutz von Fotovoltaikzellen.

Tel. 0201 177-01, www.evonik.de Kunststoff- und Gummibereich ein-

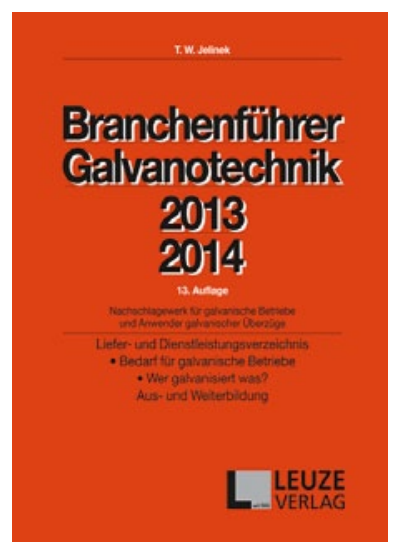

\section{Branchenführer Galvano-}

\section{technik 2013/2014}

as neu erschienene Nachschlagewerk ist sowohl für Galvanotechniker und leitende Mitarbeiter in galvanischen Betrieben als auch in produzierenden metallbe- und -verarbeitenden Unternehmen bestimmt, in denen galvanische Überzüge angewandt werden. Vor allem Betriebsleiter, Techniker, Konstrukteure, Technologen, Planer, Kontrolleure und Einkäufer sind angesprochen. Während der Textteil fachliche Informationen vermittelt, gibt der Einkaufsberater galvanischen Betrieben eine Übersicht über Lieferanten von Anlagen, Chemikalien, Hilfsmittel, Entsorgung und Beratung, während er Anwendern das Dienstleistungsangebot von mehr als 350 galvanischen Lohnbetrieben vermittelt.

13. Auflage, erschienen im Eugen G. Leuze Verlag KG, ISBN-Nr. 978-3-87480-276-5, Preis: 55 Euro

\title{
Einbauadapter für Beizbad-Sensorik
}

- ür die Konzentrationsmessung in - Beiz- und Ätzbädern hat die Firma Sensotech einen Einbauadapter für ih-

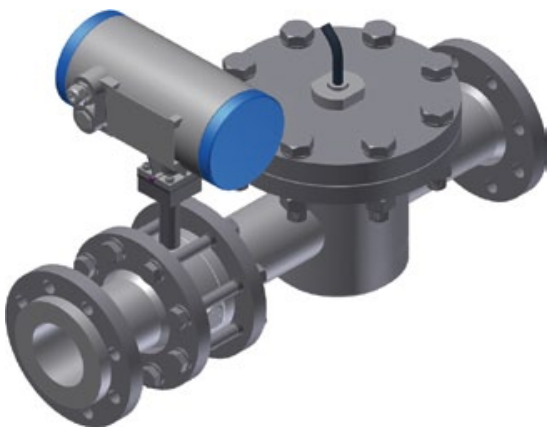

re Liquisonic-Sensoren entwickelt. Mit dem Adapter lassen sich der Rohrsensor DN 80 und der Leitfähigkeitssensor in Rohrleitungssysteme integrieren. Der Einbauadapter ist für Rohrleitungssysteme mit Nennweiten von DN 80, 3" oder 4" erhältlich. Die Gesamtlänge der Messstrecke beträgt im Einbauadapter nur maximal $1 \mathrm{~m}$, sodass die Sensorik platzsparend installiert werden kann. Der Einbauadapter besteht aus Polyvinylidenfluorid (PVDF) und ist damit thermisch und chemisch beständig, beispielsweise gegenüber
Salz- und Schwefelsäure. Die maximale Einsatztemperatur beträgt $100^{\circ} \mathrm{C}$ bei einem Betriebsdruck von maximal 0,8 bar. Der Einbauadapter besteht aus einem Messadapter für den Leitfähigkeitssensor einschließlich Gegenflansch und Leitungsadaptern für den Einbau in Rohre mit der entsprechenden Nennweite. Hinzu kommen Dichtungen und Montagematerial. Der Einbauadapter wird zusammen mit der Sensorik fertig montiert an den Kunden ausgeliefert.

Tel. 039203 514100, www.sensotech.com 